\title{
Cyclic triaxial tests to aid offshore pile analysis and design
}

1 Way Way Sim MEng, MSC, PhD, ACGI, DIC Lecturer, Geotechnics Section, Department of Civil and Environmental Engineering, Imperial College London, London, UK

2 Amin Aghakouchak MSC, DIC Doctoral Student, Geotechnics Section, Department of Civil and Environmental Engineering, Imperial College London, London, UK
3 Richard James Jardine MSc, PhD, DIC, FREng, FCGI, FICE Professor, Geotechnics Section, Department of Civil and Environmental Engineering, Imperial College London, London, UK
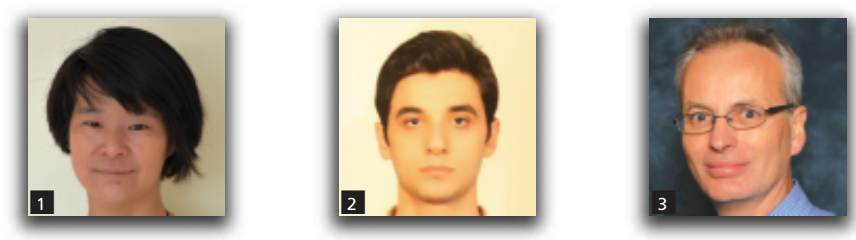

Renewable offshore energy structures experience unusually high levels of cyclic loading under storm and operating conditions. Laboratory and full-scale tests provide one route to develop rational foundation design approaches for such structures. Analytical approaches may also be developed from soil element testing and modelling. This paper outlines preliminary results from such a study. Computer-controlled stress path triaxial equipment, employing highresolution local strain instrumentation, is adopted for experiments on Dunkerque and Fontainebleau sands designed to support parallel full-scale field and laboratory-model testing programmes involving axial pile loading. The triaxial experiments comprise suites of constant-volume uniform cyclic tests on $K_{0}$ over-consolidated specimens employing different amplitudes, performed in conjunction with static and multi-stage experiments that examine the effects of non-uniform cyclic loading. Preliminary results reveal the relationships between cyclic deviator stress, mean effective stress changes and number of cycles, as well as patterns of permanent and cyclic strain development.

\section{Notation}

$D_{\mathrm{r}} \quad$ relative density

$d_{10}$ particle diameter at which $10 \%$ of the mass distribution is smaller

$d_{50} \quad$ mean mass particle diameter

$d_{90} \quad$ particle diameter at which $90 \%$ of the mass distribution is smaller

e void ratio

$e_{\max }$ maximum void ratio

$e_{\min }$ minimum void ratio

$G \quad$ shear stiffness

$G_{\mathrm{s}} \quad$ specific gravity

K soil stiffness

$K_{0} \quad$ coefficient of earth pressure at rest

$N \quad$ number of cycles

$p^{\prime} \quad$ mean effective stress

$p_{0}^{\prime} \quad$ initial mean effective stress, prior to cyclic loading

$q \quad$ deviator stress

$\bar{q} \quad$ mean deviatoric stress during cyclic loading

$q_{\mathrm{c}} \quad$ cone tip resistance

$q_{\text {cyc }} \quad$ amplitude of deviatoric cyclic loading

$q_{0} \quad$ initial deviator stress, prior to cyclic loading

$R \quad$ pile radius

$r \quad$ radial coordinate in cylindrical coordinate system $t$

time interface dilation

effective interface angle of friction coordinate system coordinate system coordinate system radial component of strain volumetric strain vertical component of strain angular component of strain radial component of stress vertical component of stress angular component of stress major principal stress minor principal stress effective radial stress at failure system angular frequency $\phi_{\mathrm{cs}}^{\prime} \quad$ critical state angle of shearing resistance

radial displacement of element adjacent to pile due to radial dimension of an element in a cylindrical

vertical dimension of an element in a cylindrical

angular dimension of an element in a cylindrical shear stress on the element in the cylindrical coordinate 


\section{Introduction}

Renewable offshore energy structures are likely to experience millions of load cycles, with variable magnitudes, frequencies and load components during their service lives. One way of assessing the potential (positive or negative) effects of such load cycling on their foundations is to conduct scaled model or fullscale tests. It is also highly valuable to develop analytical treatments that recognise and address the key soil response properties to help interpret and then apply the outcomes of either model studies or full-scale monitoring. In the same way, knowledge of how soils respond to cycling is vital to the calibration of constitutive models applied in any purely theoretical treatment.

A broad range of foundation types may be considered for offshore energy projects, including monopiles, gravity base structures and tripods or jackets founded on conventional offshore driven piles (Gavin et al., 2011). Multi-pile structures founded on driven piles rely principally on the axial shaft capacities available under cyclic conditions to resist the important cyclic moment loading imposed by renewable energy structures, such as wind turbines. Both field and laboratory tests using highly instrumented model piles, such as Bond and Jardine (1991), Lehane et al. (1993), Klotz and Coop (2001) and White and Lehane (2004), have improved understanding of driven pile behaviour during installation, equalisation and axial loading. Axial cyclic tests on full-scale piles by Jardine and Standing (2000) demonstrated that low-level cyclic loading can improve pile capacity, whereas high-level cyclic loading can be highly detrimental to shaft capacity. Field tests on instrumented piles by Gavin and O'Kelly (2007) found that cycling may counteract radial effective stress and shaft capacity gains associated with driven pile installation. The shaft capacities of their instrumented field piles were observed to reduce most sharply over the initial stages of high cyclic load tests. Recent reduced-scale mini-Imperial College pile (ICP) experiments in a pressurised calibration chamber have given further insights into the stresses developed around, and the shear zones formed adjacent to, piles driven in sand (Yang et al., 2010). Cyclic experiments with the same equipment by Tsuha et al. (2012) have helped to explain the mechanisms underlying the field behaviour reported by Jardine and Standing (2000) and identified the conditions under which 'stable', 'meta-stable' or 'unstable' responses may be expected. Simple approaches to assessing axial cyclic loading effects have been proposed by Jardine et al. (2005) and Jardine and Standing (2012), while Le Blanc et al. (2010a, 2010 b) suggest how the effects of lateral cyclic loading may be approached by means of small-scale model tests.

Any soil testing designed to gather information relevant to pile behaviour needs to consider the likely stress conditions around the piles, which can be greatly modified by pile installation. Yang et al. (2010) and Tsuha et al. (2012) show that pile driving in sands generates extremely high stresses in the surrounding soil as the pile tip passes. These stresses relax by one to two orders of magnitude close to the pile (but to progressively lesser degrees further from the shaft) as the pile tip penetrates through any given layer and advances to greater depths. A dense and compacting interface shear zone also develops under the intense localised shearing conditions developed around the tip and the shaft. Installation by driving or multi-stroke jacking also imposes a history of local high-level cyclic loading. After installation the soil surrounding the shaft is left in a highly over-consolidated, pre-sheared and pre-cycled state. The expressions given by Jardine et al. (2005) indicate that the radial effective stresses expected at points located several diameters above the tips of driven piles may be of the order of $1-2 \%$ of the local cone penetration test (CPT) tip resistances $q_{\mathrm{c}}$. To be realistic, cyclic laboratory soil element tests must attempt to match comparable initial conditions.

Most cyclic laboratory testing programmes conducted to aid design of offshore engineering projects apply trains of uniform load-controlled cycles and then observe the soil's response, often under undrained conditions: see Andersen (2009). Assumptions then have to be made as to how these uniform cyclic experiments can be used to predict the highly non-uniform loading histories that develop during critical storm events, or under lower level service loading conditions. The simple rule proposed by Miner (1945) is often invoked to assess the cumulative effects of nonuniform cycling. For example, Wichtmann et al. (2010) applied the theory to drained cyclic triaxial tests on sands while Le Blanc et al. (2010a, 2010b) applied the approach to consider model monopile lateral loading test results. It is common to use a rainflow cycle counting method to extend the uniform load cycle test results to calculate the potential effects of non-uniform cycling (Le Blanc et al., 2010a; Merritt et al., 2012; Rychlik, 1987).

The research testing reported in this paper first aims to address the cyclic conditions developed in the field and model cyclic axial tests on displacement piles installed in dense to medium dense, normally consolidated Dunkerque and Fontainebleau sands, as reported by Jardine and Standing (2000) and Tsuha et al. (2012). The initial objective was to match the cyclic conditions as closely as possible with stress-path triaxial experiments.

The field and laboratory research summarised by Jardine et al. (2005) identified the key factors controlling the static shaft capacity of piles driven in sands. As noted by Lehane et al. (1993), the local shaft shear stresses, $\tau_{\mathrm{rz}}$, reach failure when the Coulomb failure criterion is satisfied

1. $\tau_{\mathrm{rz}}=\sigma_{\mathrm{rf}}^{\prime} \tan \delta^{\prime}$

where for a given soil and pile the interface friction angle, $\delta^{\prime}$, is fixed by its granulometry and may be determined from ring shear interface tests (Yang et al., 2010). The key parameter of interest is then the radial effective stress, $\sigma_{\mathrm{rf}}^{\prime}$, acting on the pile at failure. Consider the straining of an element of soil adjacent to the shaft 
of an incompressible pile, as depicted in Figure 1, if $\varepsilon_{\theta}$ is zero owing to symmetry and $\varepsilon_{\mathrm{z}}$ is zero if the pile does not slip against the shaft. The compressive strain of the pile itself is typically only $1-2 \%$ of the local shear strains in the soil. Under these conditions the radial strain is the only possible normal strain component in the cylindrical coordinates shown. The response of the radial effective stress, $\sigma_{\mathrm{r}}^{\prime}$, to any further loading is then dependent on the restraint provided by the surrounding soil mass. The change in local radial stress, $\delta \sigma_{\mathrm{r}}^{\prime}$, developed on the shaft as a response to the shaft loading generating a local radial dilation or contraction $\Delta r$ over the thin interface shear zone, can be related to the shear stiffness of the surrounding sand and the pile radius through elastic cavity expansion, as indicated by Equation 2 (Boulon and Foray, 1986). Jardine et al. (2005) argue that under static loading to failure the outward radial displacement, $\Delta r$, is approximately equal to the peak-to-trough centreline average roughness of the pile surface. Provided that strains remain very small and the shear stiffness is linear, the relationship given by Equation 2 describes a constant normal stiffness (CNS) boundary condition, where $K$ is the numerical CNS value.

2. $\frac{\delta \sigma_{\mathrm{r}}^{\prime}}{\delta r}=\frac{2 G}{R}=K$

Laboratory shear tests can be devised to apply constant CNS conditions (see Boulon and Foray, 1986) to mimic the near-field pile loading boundary conditions. However, sands' shear stiffnesses are non-linear, pressure dependent and anisotropic. Also the CNS value varies inversely with pile radius. These factors can make it hard to pick precisely appropriate CNS values. One upper bound approach is to perform constant volume tests, in which case the CNS is infinite.

Cyclical loads applied to the heads of piles driven in sand lead to corresponding cycles in the local shear stresses $\tau_{\mathrm{r} z}$ developed on

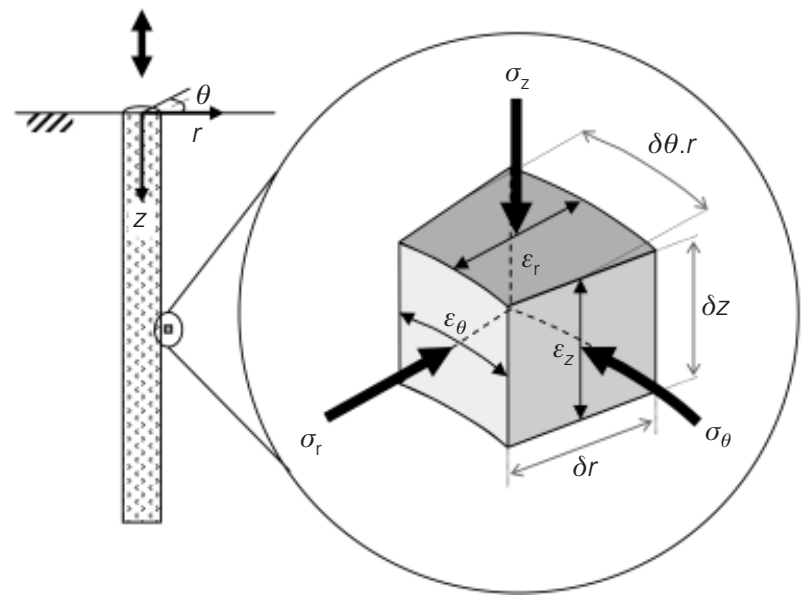

Figure 1. Schematic diagram of soil element adjacent to the pile shaft the shaft; see Jardine $(1991,1994)$. The equivalence in loading between the pile shaft and constant volume simple shear or CNS shear tests is easily established because of their analogous stressstrain boundary conditions. However, conventional simple shear tests provide an incomplete description of the sample's stress states: neither invariant effective stress paths nor Mohr circles of stress can be drawn. Hollow cylinder apparatus (HCA) simple shear tests have limitations, including some stress non-uniformities, among others (Hight et al., 1983), but they are acknowledged as providing better test conditions than conventional simple shear tests (Tatsuoka et al., 1982), and therefore will be performed as part of the authors' research programme.

A correspondence can also be made with the simpler triaxial experiments that have been performed at the start of the present research. The shear stress changes $\tau_{\mathrm{rz}}$ developed on the pile shaft pile and the triaxial deviator stress $q=\left(\sigma_{1}-\sigma_{3}\right)$ can be interrelated in terms of general stress invariants, or by simply noting that in a Mohr circle analysis increments of pure shear shaft shear loading $\tau_{\mathrm{rz}}$ have an equivalent effect to an increment in $q$ that is numerically twice as large. In the same simplified way, any change observed in mean effective stress, $p^{\prime}$, due to cyclic loading in the triaxial cell can be seen as implying an approximately equivalent proportional change in $\sigma_{\mathrm{r}}^{\prime}$ at points close to the shaft (Figure 1).

While mixed triaxial test boundary conditions can be designed to mimic CNS restraint, in either triaxial or HCA tests, constantvolume tests provide a convenient and safe initial upper bound approach. Provided the samples are fully saturated, overall constant volume can be assured by conducting the cycling under undrained conditions. More sophisticated arguments and cyclic stress controls can of course be made in cases where detailed information is available about the general state of stress around the pile shaft.

\section{Testing strategy}

Noting the above arguments and considerations, the initial triaxial cyclic experimental programme comprised suites of undrained triaxial tests that were performed in a modified, computercontrolled Bishop and Wesley (1975) stress path cell equipped with high-resolution submersible linear variable differential (LVDT) local strain transducers (Cuccovillo and Coop, 1997). The aims were to examine the effects of both uniform and nonuniform cyclic shear stress cycles on medium dense Dunkerque and Fontainebleau sands. The key features of interest were the mean effective stress and cyclic (permanent and transitory) strains. The samples were formed using a water pluviation technique and were consolidated anisotropically to accentuate the inherent anisotropy of their soil fabric (Oda et al., 1985). Noting the stress states expected after pile installation, as discussed above, and the loading capacity of the triaxial apparatus, a global over-consolidation ratio (OCR) of 4 was chosen to reflect an average stress history for sand positioned both near to the shaft and at slightly more radially distant locations. The effective stress 
path applied to reach this level of over-consolidation followed nominal $K_{0}$ paths in both consolidation and swelling, set to be the same for both the test sands so that the two materials could be compared against the same stress history. The $K_{0}$ path of the samples in swelling was designed to give the target $\mathrm{OCR}=4$. This choice positioned the starting stress state well away from the static failure line, enabling the cyclic behaviour of the sand to be studied over a high number of cycles without invoking cyclic mobility. The pre-cycling mean effective stress level, $p_{0}^{\prime}$, was selected to fall around $1 \%$ of the CPT $q_{\mathrm{c}}$ values demonstrated in the parallel field pile and large calibration chamber pile tests by CPT soundings conducted on site at Dunkerque and in the laboratory on pressurised Fontainebleau sand. Both sets of CPT tests showed mid-range $q_{\mathrm{c}}$ values around $20 \mathrm{MPa}$.

The set-up conditions for the triaxial samples of both sands were chosen to replicate the in situ field conditions of the Dunkerque pile tests (Jardine and Standing, 2000, 2012) and the calibration chamber tests in the Fontainebleau NE34 test sand (Tsuha et al., 2012; Yang et al., 2010). Chow (1997) indicates that for the Dunkerque field tests the average $D_{\mathrm{r}}$ with depth is around $75 \%$ with a maximum of $80 \%$ and initial OCR close to unity, whereas the normally consolidated Fontainebleau sand used in the calibration chamber tests by Yang et al. (2010) and Tsuha et al. (2012) employed a target $e=0 \cdot 62$, equivalent to a $D_{\mathrm{r}}=72 \%$. In order to allow the cyclic triaxial tests on the two material types to be comparable, an initial $e=0.63$, equivalent to a $D_{\mathrm{r}}=71 \%$ and $78 \%$ for the Dunkerque and Fontainebleau sands respectively, was selected to represent their respective field and model tests.

\subsection{Test materials}

The Dunkerque sand was sampled at shallow depth from PortOuest, Dunkerque, France at the site employed by Jardine and Standing (2000). The Fontainebleau sand was acquired from fresh processed batches of NE34 sand quarried from the Nemours site, south of Paris. The basic index properties of the test sands are presented in Table 1. Both sands are predominantly siliceous; the Dunkerque sand contains fractions, up to $10 \%$, of carbonate shell fragments (Kuwano, 1999). The particle size distributions of both sands are presented in Figure 2, showing that the marine Dunkerque sand has a wider range of particle sizes in comparision with the industrially graded NE34 Fontainebleau test sand. Laser analysis of the particles using a QicPic system also reveals that on average the marine Dunkerque sand has a lower sphericity and more elongated particles than Fontainebleau NE34. Earlier work by Kuwano (1999), Chow (1997), Yang et al. (2010) and Altuhafi and Jardine (2011) established the critical state and peak

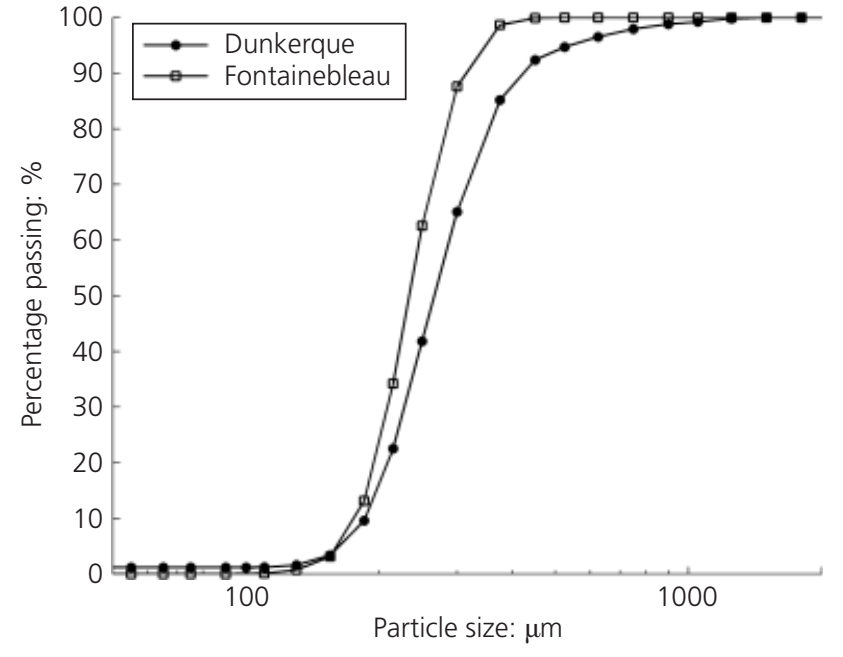

Figure 2. Particle size distribution of Dunkerque and Fontainebleau test sands

shear strength characteristics of the two sands, with the latter being dependent upon the applied effective stress level as well as the void ratio at which the sand is tested. Triaxial compression and direct shear box tests performed by Kuwano (1999) on Dunkerque sand indicate values of $\phi_{\mathrm{cs}}^{\prime}$ to be $32^{\circ}$ and $31^{\circ}$ respectively. New triaxial compression tests performed by the authors on the Fontainebleau sand gave slightly higher $\phi_{\mathrm{cs}}^{\prime}$ relative to Dunkerque sand, averaging at $32 \cdot 6^{\circ}$, comparable to the $\phi_{\mathrm{cs}}^{\prime}=33^{\circ}$ reported by Altuhafi and Jardine (2011) in triaxial compression and $\phi_{\mathrm{cs}}^{\prime}=32.8^{\circ}$ from direct shear box tests reported by Yang et al. (2010). Altuhafi and Jardine (2011) give further information on the sand's behaviour under high pressures, while Kuwano (1999) describes in greater detail the non-linear stiffness behaviour of Dunkerque sand over a wide range of stress conditions.

The normally consolidated $K_{0}$ of Dunkerque sand has been reported by Kuwano (1999) to vary between 0.35 and 0.4 from triaxial tests reducing with relative density, while Gaudin et al. (2005) report comparable variations in the $K_{0}$ for Fontainebleau sand with values between 0.34 and 0.47 from cone pressuremeter tests performed in a centrifuge. Comparing these experimental values to those calculated from Jaky's (Jaky, 1944) expression of $K_{0}$ for normally consolidated sand of 0.47 and 0.45 for Dunkerque sand and Fontainebleau sand (evaluated from $\phi_{\mathrm{cs}}^{\prime}$ ) respectively, the value of 0.45 was chosen to represent $K_{0}$ for normal consolidation of the samples. There is little information available

\begin{tabular}{|c|c|c|c|c|c|c|c|c|}
\hline Test sand & $G_{s}$ & $e_{\max }$ & $e_{\min }$ & $d_{10}: \mu \mathrm{m}$ & $d_{50}: \mu \mathrm{m}$ & $d_{90}: \mu \mathrm{m}$ & Sphericity & Elongation \\
\hline Dunkerque & $2 \cdot 65$ & 0.91 & 0.57 & $188 \cdot 4$ & $268 \cdot 8$ & $426 \cdot 6$ & 0.89 & 0.51 \\
\hline Fontainebleau & $2 \cdot 65$ & 0.90 & 0.51 & $175 \cdot 7$ & $234 \cdot 5$ & $316 \cdot 3$ & 0.89 & 0.54 \\
\hline
\end{tabular}

Table 1. Properties of test sands 
Geotechnical Engineering Volume 166 Issue GE2
Cyclic triaxial tests to aid offshore pile analysis and design

Sim, Aghakouchak and Jardine experimentally on the $K_{0}$ of over-consolidated Dunkerque or Fontainbleau sands, but applying the expression for $K_{0}$ for overconsolidated soils by Mayne and Kulhawy (1982) gives nominal $K_{0}$ values of 0.98 and 0.97 for Dunkerque sand and Fontainebleau sand respectively. The experimental advantages in applying final consolidation states that fall further away from the isotropic axis than implied by the above $K_{0}$ estimates are discussed in greater detail later in the following section.

\subsection{Set-up and consolidation}

A modified Bishop and Wesley (1975) type $38 \mathrm{~mm}$ triaxial cell, with computer control, internal and external displacement sensors

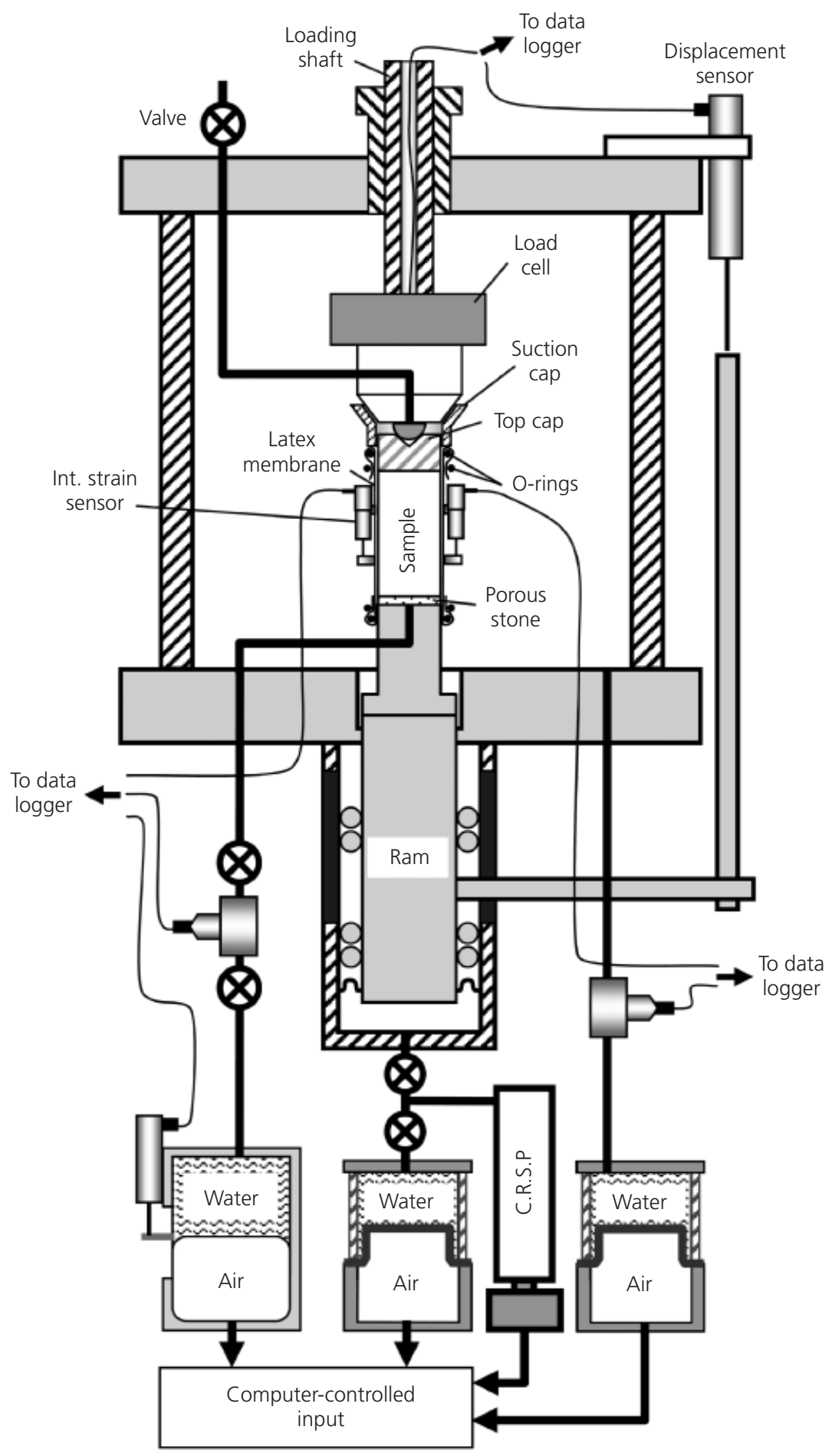

Figure 3. Schematic diagram of triaxial apparatus set-up (CRSP = constant rate of strain pump) 
was used for the preliminary tests. A schematic representation of the apparatus is shown in Figure 3. Samples of both sands were saturated and de-aired in a vacuum before being water pluviated through a funnel into a latex-membrane-lined mould, to generate samples $38 \mathrm{~mm}$ in diameter and $76 \mathrm{~mm}$ high, at a target $e$ of 0.63 ; equivalent to $D_{\mathrm{r}}$ of $71 \%$ and $78 \%$ for the Dunkerque and Fontainebleau sands respectively. All the samples were then saturated by applying a back pressure of $280 \mathrm{kPa}$, while maintaining an effective stress of $20 \mathrm{kPa}$ to achieve a minimum B-value of $0 \cdot 95$. The samples were then anisotropically consolidated along a nominal $K_{0}(=0.45)$ path from a mean effective stress, $p^{\prime}$, of $20 \mathrm{kPa}$ (point A, Figure 4) at a constant rate of stress change to a deviator stress, $q$, of $440 \mathrm{kPa}$ and mean effective stress, $p^{\prime}$, of $506 \mathrm{kPa}\left(\sigma_{\mathrm{z}}^{\prime}=800 \mathrm{kPa}, \sigma_{\mathrm{r}}^{\prime}=360 \mathrm{kPa}, \sigma_{\mathrm{r}}^{\prime} / \sigma_{\mathrm{z}}^{\prime}=0 \cdot 45\right.$, point $\mathrm{B}$, Figure 4). The samples were allowed to creep for $12 \mathrm{~h}$ before swelling to $q=q_{0}=\bar{q}=50 \mathrm{kPa}$ and $p^{\prime}=p_{0}^{\prime}=167 \mathrm{kPa}$ to achieve an OCR of $4\left(\sigma_{\mathrm{z}}^{\prime}=200 \mathrm{kPa}, \sigma_{\mathrm{r}}^{\prime}=150 \mathrm{kPa}, \sigma_{\mathrm{r}}^{\prime} / \sigma_{\mathrm{z}}^{\prime}=0 \cdot 75\right.$, point $\mathrm{C}$, Figure 4). The $K_{0}$ imposed during swelling of the sample from point B to C, Figure 4, was set to be lower than the values of $K_{0}$ for over-consolidated samples estimated using Mayne and Kulhawy's (Mayne and Kulhawy, 1982) expression to allow all of the intended cycles to be applied without crossing the isotropic axis. Crossing the isotropic axis during cyclic loading can cause unintended minor perturbations in the measured deviator force, related to the load cell's construction.

\subsection{Undrained cyclic loading}

Prior to application of cyclic loading a further $12 \mathrm{~h}$ creep period allowed the sample to stabilise before applying the undrained cycles of deviator stress. A range of cyclic amplitude, $q_{\text {cyc }}$, values, expressed as a proportion of the initial applied mean effective stress, $p_{0}^{\prime}$, were applied under undrained conditions, under constant radial cell pressure, as a sine wave function to the deviator stress, $q$, at a frequency of $1 \mathrm{cycle} / \mathrm{min}$ that allowed accurate load control and close data logging. Samples were subjected to a total of 1500 cycles in each test stage, as indicated by Figure 5 .

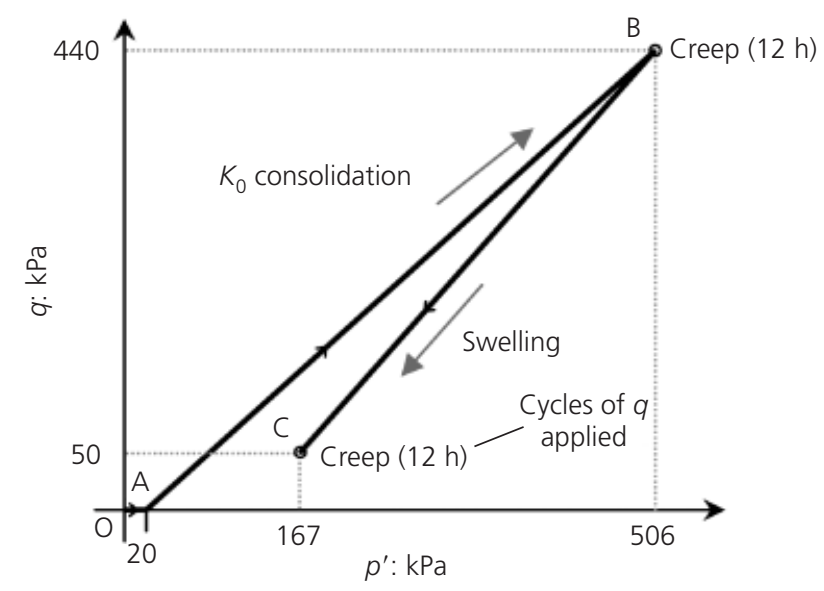

Figure 4. Sample stress path prior to cyclic loading

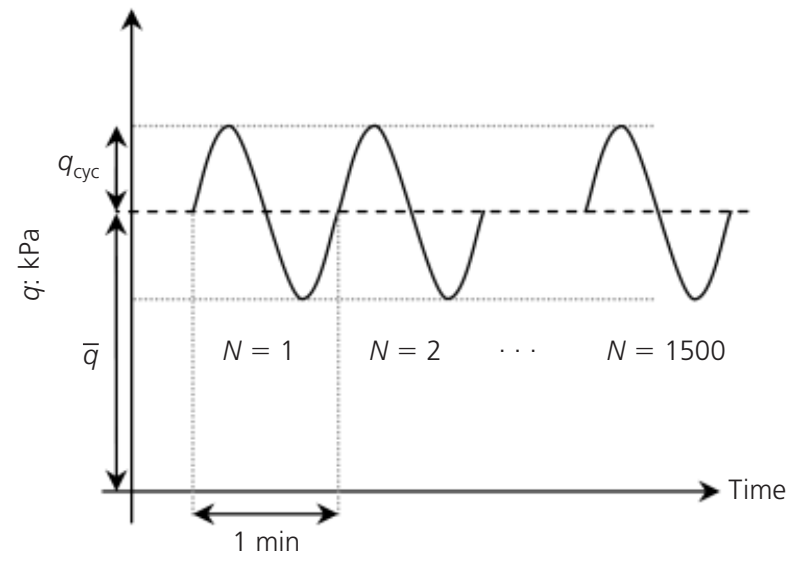

Figure 5. Schematic diagram of cyclic loading scheme applied

The experiments aimed to examine the effect of amplitude of cycles on the generation of excess pore water pressure, permanent and cyclic strains with number of cycles. The cyclic loading terms are defined in Figure 5, with $q_{\text {cyc }}$ being the deviatoric stress amplitude varying about a mean deviatoric stress, $\bar{q}$ (Equation 3 ). The loads were applied through the in-house control program Triax (Toll, 1993) with a stress tolerance of $\pm 0 \cdot 5 \mathrm{kPa}$.

$$
\text { 3. } q=\bar{q}+q_{\mathrm{cyc}} \sin (\omega t)
$$

The cyclic triaxial tests performed in the preliminary test series on Dunkerque and Fontainebleau sands are listed in Tables 2 and 3 , respectively.

The preliminary series included experiments to examine the

\begin{tabular}{lccc}
\hline Test name & Initial $D_{\mathrm{r}}: \%$ & $q_{\mathrm{cyc}}: \mathrm{kPa}$ & $q_{\mathrm{cyc}} / p_{0}^{\prime}: \%$ \\
\hline D05 & $77 \cdot 4$ & $8 \cdot 4$ & 5 \\
D10 & $79 \cdot 4$ & $16 \cdot 7$ & 10 \\
D15 & $77 \cdot 0$ & $25 \cdot 1$ & 15 \\
D20 & $76 \cdot 8$ & $33 \cdot 4$ & 20 \\
D27 & 78.0 & $45 \cdot 0$ & 27
\end{tabular}

Table 2. Tests on Dunkerque sands

\begin{tabular}{lccc}
\hline Test name & Initial $D_{\mathrm{r}}: \%$ & $q_{\mathrm{cyc}}: \mathrm{kPa}$ & $q_{\mathrm{cyc}} / p_{0}^{\prime}: \%$ \\
\hline F07 & $71 \cdot 8$ & $11 \cdot 7$ & 7 \\
F10 & $69 \cdot 2$ & 16.7 & 10 \\
F15 & $71 \cdot 7$ & $25 \cdot 1$ & 15 \\
F20 & 71.8 & 33.4 & 20 \\
F25 & 69.2 & 41.8 & 25
\end{tabular}

Table 3. Tests on Fontainebleau sands 
effects of different sequences of non-uniform cyclic loading to the reduction of mean effective stress due to the imposed cycles of deviatoric stress; effectively examining Miner's rule. Tests D10, F10 and F25 were extended after the end of their first 1500 uniform cycles as multi-stage experiments. Additional batches, each involving a further 1500 cycles of deviatoric load, were applied at the same frequency but at different (higher or lower) $q_{\text {cyc }}$ values than the previous batch (Figure 6). One multi-stage test was performed on Dunkerque sand and two on the Fontainebleau sand; see Table 4 . The test names assigned to each multistage test represent the order of the $q_{\text {cyc }}$ values applied for each batch of 1500 cycles, so D10-20-10 denotes a Dunkerque sand specimen subjected to 1500 cycles of $q_{\mathrm{cyc}}=10 \% p_{0}^{\prime}$, followed by 1500 cycles of $q_{\mathrm{cyc}}=20 \% p_{0}^{\prime}$, and then a further 1500 cycles of $q_{\mathrm{cyc}}=10 \% p_{0}^{\prime}$, as shown schematically in Figure 6 .

\section{Preliminary test results}

The initial void ratios of the Dunkerque samples averaged at $0.638 \pm 0.006$ at set-up, while the Fontainebleau samples averaged at $0.627 \pm 0 \cdot 006$, using water pluviation. The applied effective stress paths followed by all samples conformed to the consolidation, creep, swelling and further creep sequence indicated in Figure 4. The control systems maintained the prescribed stress path to within the accuracies of the stress measuring systems, which typically fall around $\pm 1 \mathrm{kPa}$. The general trend of the compression and swelling behaviour of the test sands is shown for two representative tests (D10 and F25) in Figure 7. The prescribed set-up procedure, prior to cyclic loading, resulted in volumetric strains of $0.85 \%$ and $0.75 \%$, on average for the tests on Dunkerque and Fontainebleau sands respectively. Most of the volumetric strain, $\varepsilon_{\mathrm{vol}}$, occurs during the consolidation stage,

\begin{tabular}{lccc}
\hline Test name & \multicolumn{3}{c}{$q_{\text {cyc }} / p_{0}^{\prime}: \%$} \\
\cline { 2 - 4 } & Stage 1 & Stage 2 & Stage 3 \\
\hline D10-20-10 & 10 & 20 & 10 \\
F10-20-10 & 10 & 20 & 10 \\
F25-10 & 25 & 10 & -
\end{tabular}

Table 4. Multi-stage test outline

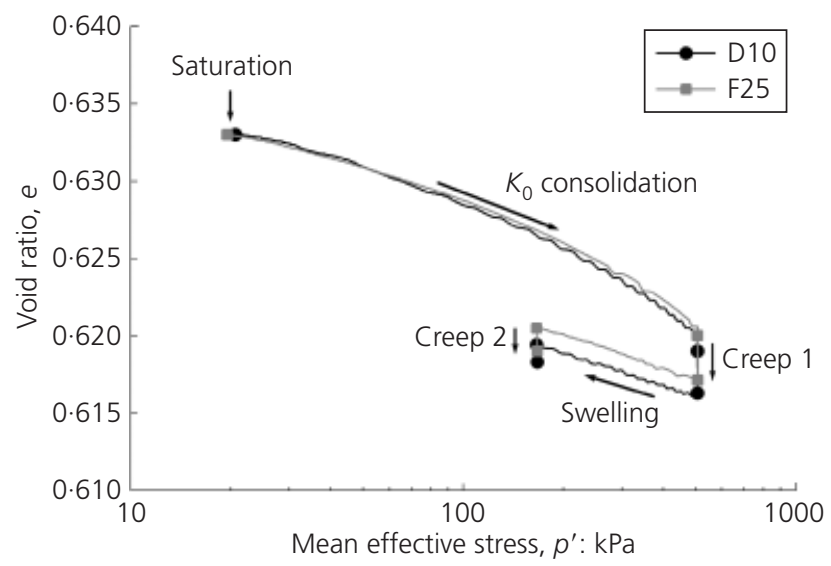

Figure 7. Typical compression and swelling behaviour for Dunkerque and Fontainebleau sands prior to cyclic loading, D10 and F25

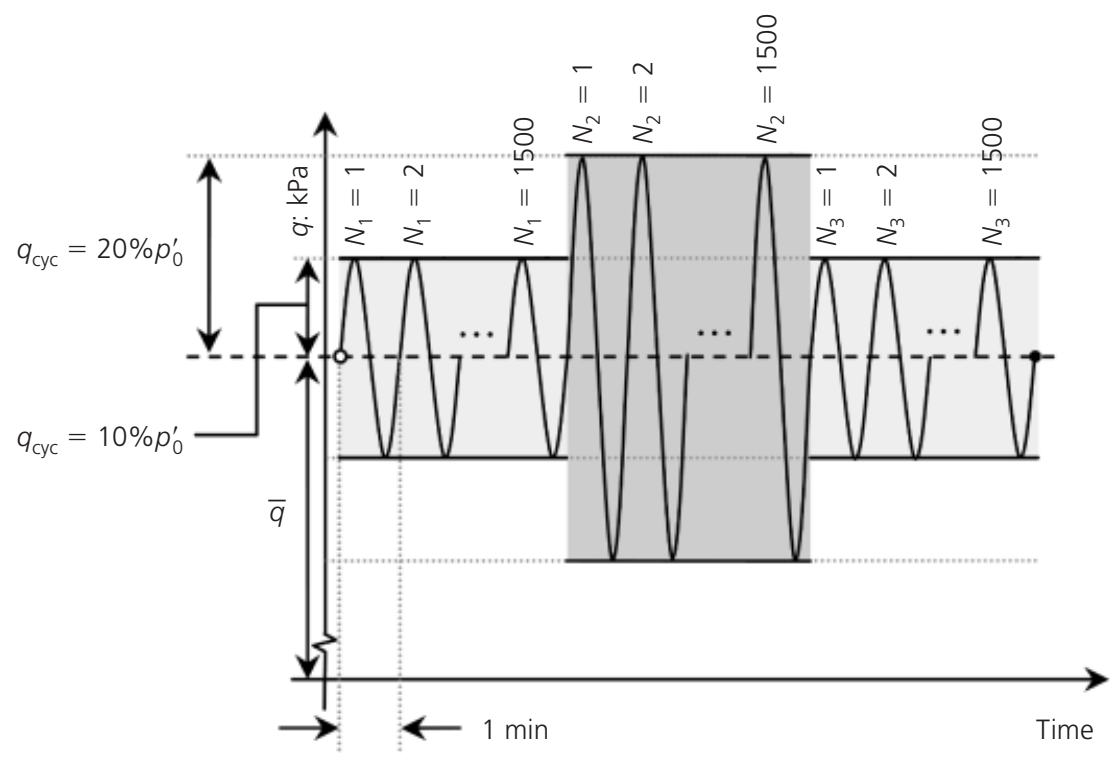

Figure 6. Schematic diagram of cyclic loading scheme applied in multi-stage tests, example of D10-20-10 and F10-20-10 
Cyclic triaxial tests to aid offshore pile

analysis and design

Sim, Aghakouchak and Jardine with a minor continuation in void ratio reduction during the first creep stage (losses of $0 \cdot 19 \%$ and $0 \cdot 15 \%$ of $\varepsilon_{\mathrm{vol}}$ for the Dunkerque and Fontainebleau sands respectively). During the following swelling stage, the samples rebounded giving volume gains, $\varepsilon_{\mathrm{vol}}$, of $0 \cdot 21 \%$ and $0 \cdot 20 \%$ for Dunkerque and Fontainebleau sands respectively, showing that behaviour during compression to $p^{\prime}=506 \mathrm{kPa}$ was plastic and predominantly irrecoverable. The final creep stages, imposed prior to cyclic loading, led to further minor losses in volume with $\varepsilon_{\mathrm{vol}}=0.05 \%$ and $0.03 \%$ for the Dunkerque and Fontainebleau sands respectively. In general the Dunkerque sand showed slightly higher compressibility and swelling coefficients and more creep; these features are perceived to be attributable to their differing relative densities, particle size distributions and shapes.

The effective stress paths developed during undrained cyclic loading with applied cyclic deviatoric amplitudes of $q_{\mathrm{cyc}}=20 \%$ $p_{0}^{\prime}$ are shown in Figure 8. The paths show a clear inclination during load cycling with positive gradients in $q-p^{\prime}$ space of 6.2 and 6.6 on average for the Dunkerque and Fontainebleau sands respectively (equivalent to 0.21 and 0.22 in $\sigma_{\mathrm{r}}^{\prime}-\sigma_{\mathrm{z}}^{\prime}$ space). The effective stress paths also show that the cyclic control systems kept the peak and trough values of $q$ to within $2 \%$ of their targets, equivalent to within $1 \mathrm{kPa}$ for $q_{\mathrm{cyc}} \leqslant 10 \% p_{0}^{\prime}$ and within $3.4 \mathrm{kPa}$ for $q_{\mathrm{cyc}}>10 \% p_{0}^{\prime}$.

\subsection{Reduction in mean effective stress, $\Delta p^{\prime} / p_{0}^{\prime}$}

\subsubsection{Single-stage cyclic loading}

As outlined previously, all of the cyclic tests involved one or more batches of 1500 undrained deviatoric stress cycles applied to freshly water pluviated, $K_{0}$ consolidated samples of clean Dunkerque and Fontainebleau sand that had been swelled to

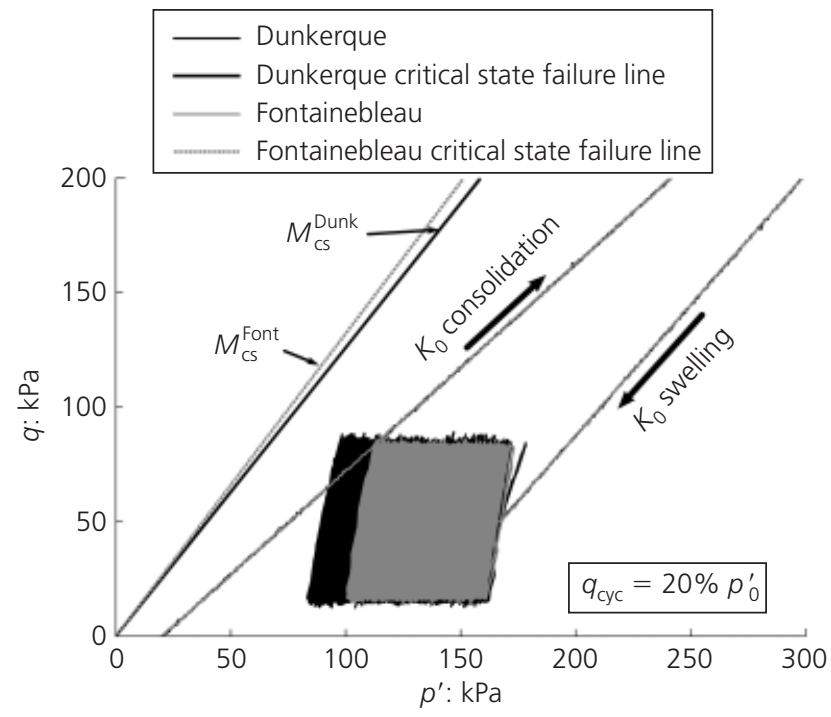

Figure 8. Typical effective stress paths and critical state $M$ values for tests performed on Dunkerque (Dunk) and Fontainebleau (Font) sand, D20 and F20, $q_{\text {cyc }}=20 \% p_{0}^{\prime}$
OCR $=4$. Each batch applied a particular fixed $q_{\text {cyc }}$ level, set in these preliminary tests between 7 and $27 \% p_{0}^{\prime}$. The effects of cycling on the effective stress states are summarised in plots showing the proportional reductions in mean effective stress, $p^{\prime}$, as for each sand in Figures 9 and 10, plotted as hollow symbols. The $p^{\prime}$ values were tracked as those measured at the crossing points of each cycle, where $q=\bar{q}=50 \mathrm{kPa}$.

It is evident from the results that

(a) $p^{\prime}$ progressively reduced with cycling even in these medium to dense sands

(b) the magnitudes of the reductions in $p^{\prime}$ increase with increasing $q_{\mathrm{cyc}} / p_{0}^{\prime}$

(c) the rates of reduction of $p^{\prime}$ reduced with the number of cycles, $N$.

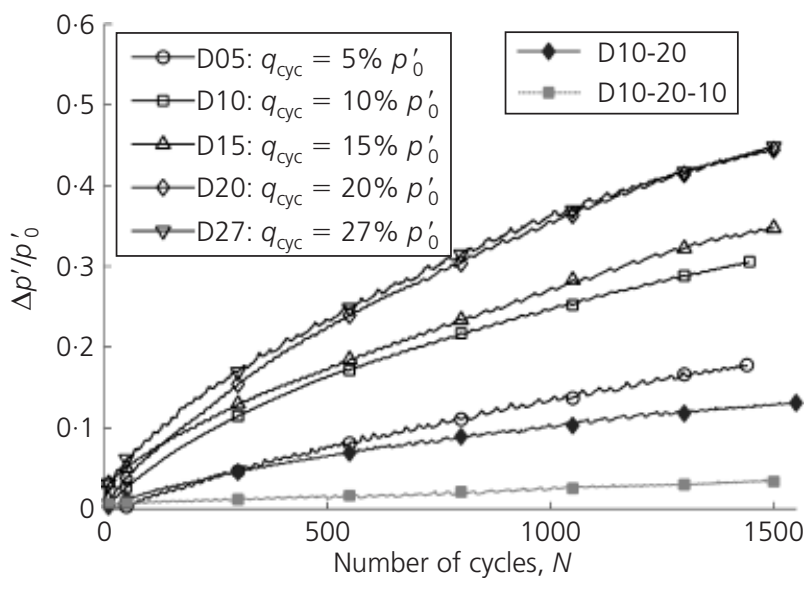

Figure 9. Dunkerque sand: reduction in mean effective stress at different values of $q_{\text {cyc }}$ (hollow symbols) and the effect of precycling on the reduction in $p^{\prime}$ (solid symbols)

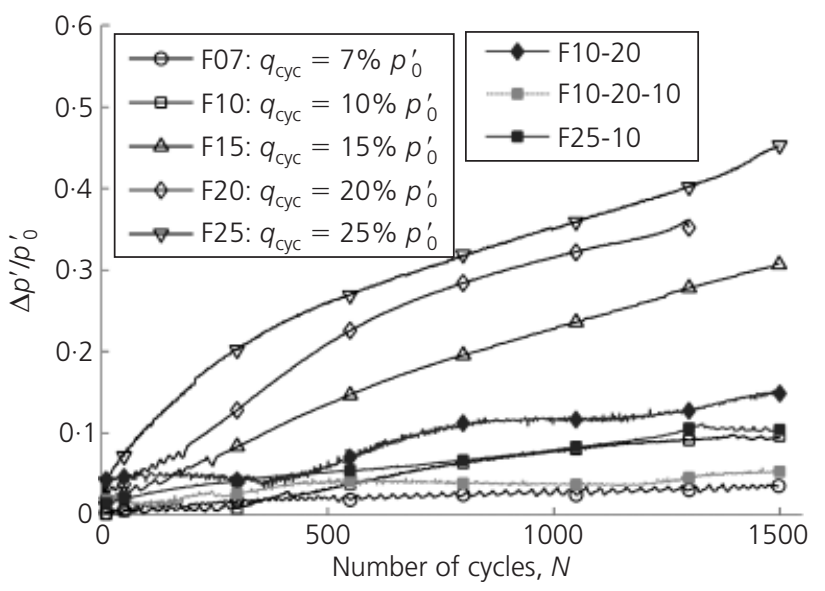

Figure 10. Fontainebleau sand: reduction in mean effective stress at different values of $q_{c y c}$ (hollow symbols) and the effect of precycling on the reduction in $p^{\prime}$ (solid symbols) 
A comparison of the single stage tests presented in Figures 9 and 10 indicates that neither sand reached a $50 \%$ loss of $p^{\prime}$ after 1500 cycles under the levels applied, and that no overall cyclic failure occurred. The different grain size distributions and shapes appear to have affected the magnitudes of $p^{\prime}$ reduction, with the Dunkerque sand exhibiting greater reductions in $p^{\prime}$ (at equivalent $q_{\text {cyc }}$ values) than the Fontainebleau sand. This effect is most pronounced at low levels of $q_{\mathrm{cyc}}$; as illustrated by $q_{\mathrm{cyc}}=10 \% p_{0}^{\prime}$ where the Fontainebleau sand exhibits $\Delta p^{\prime} / p_{0}^{\prime}=-10 \%$ (reduction) and the Dunkerque sand a $\Delta p^{\prime} / p_{0}^{\prime}=-30 \%$ reduction after 1500 cycles.

\subsubsection{Multi-stage cyclic loading}

The multi-stage tests were performed to examine the impact of variable sequences of constant amplitude loading. The results are presented as solid filled symbols in Figures 9 and 10, which display the undrained reductions of $p^{\prime}$ for stages 2 and 3 (where applied) in comparison with the reduction in $p^{\prime}$ due to cyclic loading for freshly pluviated samples at different levels of $q_{\text {cyc }}$. Where prior undrained cyclic loading had been applied the subsequent rates of reduction in $p^{\prime}$ were much lower than those exhibited under the same $q_{\text {cyc }}$ by a freshly prepared (consolidated, swelled, aged) and previously uncycled sample.

\subsubsection{Permanent and cyclic strains}

Although the undrained cyclic tests contracted readily and showed very clear changes in mean effective stresses, the strains developed remained very small. The sands are both very stiff in shear and the axial strains measured at $q=\bar{q}$ remained below $0.01 \%$ in all tests. The rates of permanent strain accumulation were clearest in the higher $q_{\mathrm{cyc}}$ level tests and these grew roughly linearly with the number of cycles to attain a maximum magnitude around $0 \cdot 005 \%$. The cyclic strain amplitudes also increased with $q_{\mathrm{cyc}}$, as expected given the sands' highly nonlinear shear stiffness characteristics, but did not change greatly as cycling continued. Relatively modest reductions in cyclic stiffness were seen, with cyclic strain amplitudes growing by no more than $40 \%$ and $20 \%$ over 1500 cycles with the Dunkerque and Fontainebleau sands respectively. The permanent strains accumulated by the end of each batch of 1500 higher-level cycles typically amounted to around double the initial cyclic amplitudes. The lower level cyclic tests were expected to show smaller proportions of permanent strain development. However, the displacements seen under low-level cycling were of comparable magnitude to the strain resolution of the LVDTs employed and the recorded trends were scattered. Measurement difficulties were exacerbated in early low-level tests by sub-optimal data logging settings that led to poorer strain measurement resolution.

\subsection{Contours of $\Delta p^{\prime} / p_{0}^{\prime}$ in $q_{\text {cyc }} / p_{0}^{\prime}-N$ space}

The preliminary cyclic stress path tests performed on the two test sands have been interpreted to express the relationships between the level of cyclic loading, the change in $p^{\prime}$ and the number of cycles, as presented in Figures 11 and 12. The trends indicate that the Dunkerque sand had a more stable response to the applied

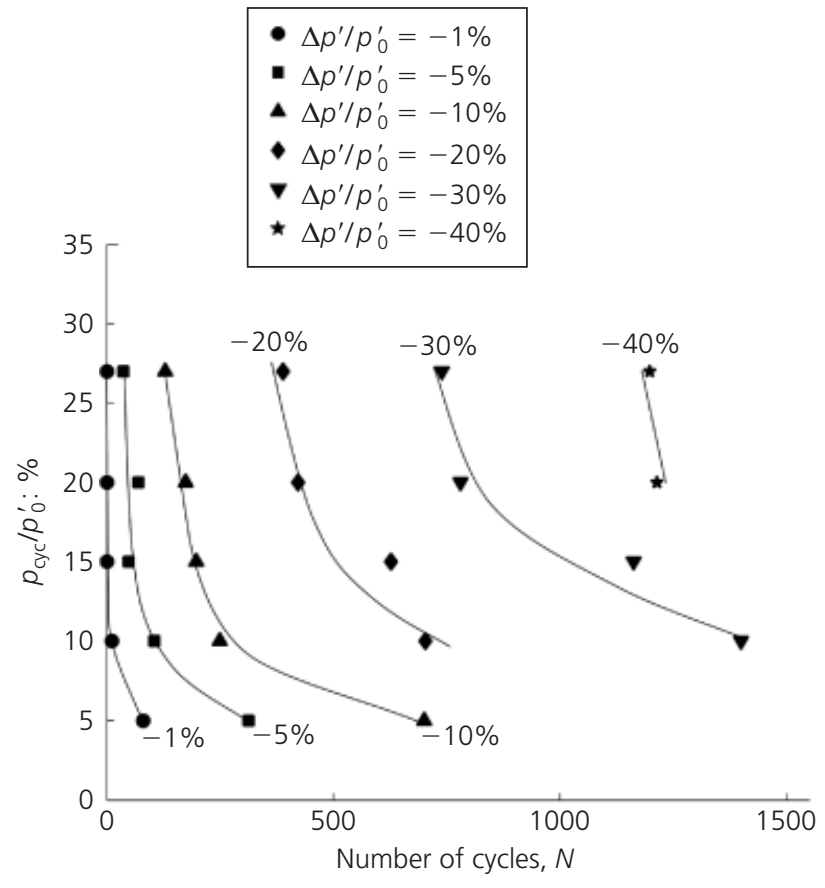

Figure 11. Contours of constant $\Delta p^{\prime} / p_{0}^{\prime}$, as percentage reduction, in relation to level of cyclic amplitude and number of cycles, Dunkerque sand

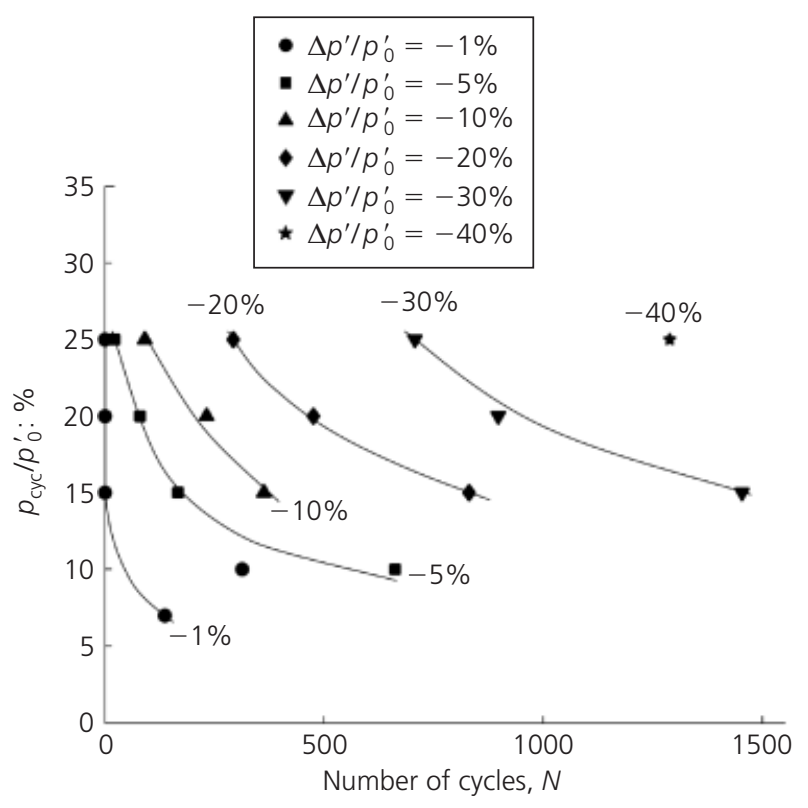

Figure 12. Contours of constant $\Delta p^{\prime} / p_{0}^{\prime}$, as percentage reduction, in relation to level of cyclic amplitude and number of cycles, Fontainebleau sand

cycles, with a less rapid loss in $p^{\prime}$ with increasing magnitude of $q_{\mathrm{cyc}}$, with the Fontainebleau sand requiring a greater level of $q_{\mathrm{cyc}}$ for the same number of cycles and $p^{\prime}$ reduction; so, for example, the interpreted trends indicate that to reach $20 \%$ loss in $p^{\prime}$ at 500 
cycles would require uniform cycling at $q_{\mathrm{cyc}}=17 \% p_{0}^{\prime}$ for Dunkerque sands and $q_{\mathrm{cyc}}=20 \% p_{0}^{\prime}$ for Fontainebleau sands.

\section{Discussion}

The undrained cyclic tests performed on the Dunkerque and Fontainebleau sands indicate that both sands are highly susceptible to constant volume cycling under the imposed triaxial conditions. Further interpretation and modelling is required to compare the preliminary laboratory trends with those seen in the field and calibration chamber model tests; this is in hand. Other tests are planned that will subject the samples to multiple highlevel cycles, as imposed by pile installation, prior to low-level cycling. Further research is also under way to examine the possible influence of the direction of the effective stress paths imposed during cycling. HCA will be employed to impose stress paths that are more closely aligned with those developed alongside pile shafts.

Comparisons between the single and multi-stage tests show that it is not reasonable to treat each new batch of cycles as if it was being applied to a fresh specimen, as shown in previous studies such as Jardine and Standing (2000) and White and Lehane (2004). Pre-cycling clearly pre-stiffened the sands and reduced their tendency to contract under deviatoric shearing. It is clearly important to carry forward a memory of the prior cyclic loading in any quantitative assessment of cyclic effects. Possible 'equivalent cycle' procedures for use in such analyses are described by Andersen (2009) and Jardine and Standing (2012). Test evaluation is continuing to examine whether Miner's rule can be applied to provide reasonable estimates for the losses in mean effective stress within triaxial samples that experience multi-stage cycling, and by extension, consider the potential radial effective stress (and hence shaft capacity) changes developed around axially cycled piles.

The potential effects of pre-cycling have already been demonstrated in the field and model pile tests by Jardine and Standing (2012) and Tsuha et al. (2012), who found that low-level cycles improve shaft capacities, whereas renewed high-level cyclic loading is highly detrimental. The preliminary findings presented above highlight the need to consider the cyclic loading of the soil mass adjacent to the pile during installation, in addition to the cyclic loads applied during its working life cycle.

The above features help to explain the trends seen in field and calibration chamber cyclic model pile tests. Further testing, interpretation and modelling is in hand to

(a) assess whether the triaxial trends are compatible with those seen in the cyclic pile tests

(b) discover whether high-level pre-cycling leads to a better approach for modelling pile tests

(c) investigate with HCA the possible influence of the stress paths imposed during cycling

(d) examine whether Miner's rule and simple 'equivalent cycle' procedures can be applied to provide reasonable estimates for the losses in triaxial test mean effective stresses and possible pile shaft capacity changes.

\section{Summary and conclusion}

This paper has set out the background to a laboratory programme of cyclic loading tests on sands designed to help interpret field and calibration chamber cyclic axial loading pile experiments. The rationale for the testing approach has been set out before, presenting preliminary results from the programme. The key points from the pilot tests reported are listed below.

(a) Despite their initially dense and over-consolidated states, both the Dunkerque and Fontainebleau sand specimens showed contractant behaviour under constant volume cyclic triaxial deviatoric testing.

(b) The experiments showed clear and systematic trends between the observed reductions in mean effective stress and (i) the imposed cyclic loading levels, (ii) the numbers of cycles experienced and (iii) the previous history of cycling.

(c) The sand samples generally showed very stiff stress-strain behaviour under the imposed load cycling, with cyclic stiffnesses reducing only gently as cycling continued.

(d) The rates of permanent strain development: (i) increased with the imposed cyclic loading levels, (ii) fell with the numbers of cycles and (iii) depended on the previous history of cycling.

(e) Suites of single and multi-stage tests investigated the effects of prior cyclic history. As with static testing, prior shearing affects the response to subsequent probing tests and it is not reasonable simply to treat each new batch of cycles as if it was being applied to a fresh specimen.

$(f)$ Pre-cycling pre-stiffens the sands' responses and reduces their tendency to contract under deviatoric shearing.

\section{Acknowledgements}

The authors express their appreciation of the technical support team at Imperial College London: Steven Ackerley, Alan Bolsher, Graham Keefe and Duncan Parker, for their assistance in performing the experimental work presented in this paper. The authors also extend their gratitude to JAMM Design and Development Engineering Co.'s sponsorship and Imperial College's Dixon scholarship of A.A. and to Atkins for their support of the research.

\section{REFERENCES}

Altuhafi F and Jardine RJ (2011) Effect of particle breakage and strain path reversal on the properties of sands located near to driven piles. In Proceedings of the 5th International Symposium on Deformation Characteristics of Geomaterials - IS-Seoul 2011, Seoul, Korea (Chung CK, Kim HK, Lee JS, Jung YH and Kim DS (eds)). Hanrimwon, Seoul, Korea, vol. 1, pp. 386-395. Andersen KH (2009) Bearing capacity under cyclic loading offshore, along the coast and on land. Canadian Geotechnical Journal 46(5): 513-535. 
Bishop AW and Wesley LD (1975) A hydraulic triaxial apparatus for controlled stress path testing. Géotechnique 25(4): 657-670.

Bond AJ and Jardine RJ (1991) Effects of installing displacement piles in a high OCR clay. Géotechnique 41(3): 341-363.

Boulon M and Foray P (1986) Physical and numerical simulation of lateral shaft friction along offshore piles in sand. Proceedings of the 3rd International Conference on Numerical Methods in Offshore Piling, Nantes, France, 127147.

Chow FC (1997) Investigation into Displacement Pile Behaviour for Offshore Foundations. PhD thesis, Imperial College London, London, UK.

Cuccovillo T and Coop MR (1997) The measurement of local axial strains in triaxial tests using LVDTs. Géotechnique 47(1): 167-171.

Gaudin C, Schnaid F and Garnier J (2005) Sand characterization by combined centrifuge and laboratory tests. International Journal of Physical Modelling in Geotechnics 5(1): 42-56.

Gavin KG and O'Kelly BC (2007) Effect of friction fatigue on pile capacity in dense sand. Journal of Geotechnical and Geoenvironmental Engineering, ASCE 133(1): 63-71.

Gavin KG, Igoe D and Doherty P (2011) Piles for offshore wind turbines: a state of the art review. ICE Geotechnical Engineering Journal 164(4): 245-256.

Hight DW, Gens A and Symes MJ (1983) The development of a new hollow cylinder apparatus for investigating the effects of principal stress rotation. Géotechnique 33(4): 355-383.

Jaky J (1944) The coefficient of earth pressure at rest. Journal for Society of Hungarian Architects and Engineers October: $355-358$

Jardine RJ (1991) The cyclic behaviour of offshore piles. In Cyclic Loading of Soils (O'Reilly MP and Brown SF (eds)). Blackie and Son, Glasgow, UK, pp. 174-248.

Jardine RJ (1994) Review of Offshore Pile Design for Cyclic Loading: North Sea Clays. Health and Safety Executive, London, UK, HSE Offshore Technology Report No. OTN 94 157. 85 .

Jardine RJ and Standing JR (2000) Pile Load Testing Performed for HSE Cyclic Loading Study at Dunkirk, France. Health and Safety Executive, London, Offshore Technology Report No. OTO 2000007.

Jardine RJ and Standing JR (2012) Field axial cyclic loading experiments on piles driven in sand. Soils and Foundations 52(4): 723-736.

Jardine RJ, Chow FC, Overy R and Standing JR (2005) ICP Design Methods for Driven Pile In Sands and Clays. Thomas Telford, London, UK.

Klotz EU and Coop MR (2001) An investigation of the effect of soil state on the capacity of driven piles in sands. Géotechnique 51(9): 733-751.

Kuwano R (1999) The Stiffness and Yielding Anisotropy of Sand. $\mathrm{PhD}$ thesis, Imperial College London, London, UK

Le Blanc C, Byrne BW and Houlsby GT (2010a) Response of stiff piles to random two-way lateral loading. Géotechnique 60(9): $715-721$.
Le Blanc C, Houlsby GT and Byrne BW (2010b) Response of stiff piles to long term cyclic loading. Géotechnique 60(2): 79-90.

Lehane BM, Jardine RJ, Bond AJ and Frank R (1993) Mechanisms of shaft friction in sand from instrumented pile tests. Journal of Geotechnical and Geoenvironmental Engineering 119(1): $19-35$.

Mayne PW and Kulhawy FH (1982) $\mathrm{K}_{0}-\mathrm{OCR}$ relationships in soil. Journal of Geotechnical and Geoenvironmental Engineering, ASCE 108(6): 851-872.

Merritt AS, Schroeder FC, Jardine RJ et al. (2012) Development of pile design methodology for an offshore wind farm in the North Sea. Proceedings of the 7th International Conference on Offshore Site Investigation and Geotechnics, London, UK, pp. 439-448.

Miner MA (1945) Cumulative damage in fatigue. Transactions of the American Society of Mechanical Engineering 12(3): A159-164.

Oda M, Nemat-Nasser S and Konishi J (1985) Stress-induced anisotropy in granular masses. Soils and Foundations 25(3): $85-97$.

Rychlik I (1987) A new definition of the rainflow cycle counting method. International Journal of Fatigue 9(2): 119-121.

Tatsuoka F, Muramatsu M and Sasaki T (1982) Cyclic undrained stress-strain behaviour of dense sands by torsional simple shear test. Soils and Foundations 22(2): 55-70.

Toll DG (1993) TRIAX User Manual. Version 3.3. Geotechnical Systems Group, Durham University, Durham, UK.

Tsuha CHC, Foray PY, Jardine RJ et al. (2012) Behaviour of displacement piles in sand under cyclic axial loading. Soils and Foundations 52(3): 393-410.

White DJ and Lehane BM (2004) Friction fatigue on displacement piles in sand. Géotechnique 54(10): 645-658.

Wichtmann T, Niemunis A and Triantafyllidis T (2010) Strain accumulation in sand due to drained cyclic loading: on the effect of monotonic and cyclic preloading (Miner's rule). Soil Dynamics and Earthquake Engineering 30(8): 736-745.

Yang ZX, Jardine RJ, Zhu BT, Foray P and Tsuha CHC (2010) Sand grain crushing and interface shearing during displacement pile installation in sand. Géotechnique 60(6): 469-482.

\section{WHAT DO YOU THINK?}

To discuss this paper, please email up to 500 words to the editor at journals@ice.org.uk. Your contribution will be forwarded to the author(s) for a reply and, if considered appropriate by the editorial panel, will be published as a discussion in a future issue of the journal.

Proceedings journals rely entirely on contributions sent in by civil engineering professionals, academics and students. Papers should be 2000-5000 words long (briefing papers should be 1000-2000 words long), with adequate illustrations and references. You can submit your paper online via www.icevirtuallibrary.com/content/journals, where you will also find detailed author guidelines. 